\title{
Salvage Robotic-assisted Laparoscopic Radical Prostatectomy: Experience with 14 Cases
}

\author{
YEN-CHUAN OU $1,2,3$, SHENG-CHUN HUNG ${ }^{1,3}$, LI-HUA HWANG ${ }^{4}$, \\ CHUN-KUANG YANG ${ }^{1,3}$, SIU-WAN HUNG ${ }^{3,5}$ and MIN-CHE TUNG ${ }^{4}$ \\ ${ }^{1}$ Division of Urology, Department of Surgery, ${ }^{2}$ Department of Research, and \\ ${ }^{5}$ Department of Radiation, Taichung Veterans General Hospital, Taichung, Taiwan, R.O.C.; \\ ${ }^{3}$ School of Medicine, National Yang-Ming University, Taipei, Taiwan, R.O.C.; \\ ${ }^{4}$ Division of Urology, Department of Surgery, Tungs' Taichung MetroHarbor Hospital, Taichung, Taiwan, R.O.C.
}

\begin{abstract}
Aim: To report the outcomes of salvage robotassisted radical prostatectomy (S-RaRP). Patients and Methods: Fourteen patients underwent S-RaRP. The mean initial prostatic-specific antigen level was $14.3 \mathrm{ng} / \mathrm{ml}$ and mean Gleason score was 6.93. Initial definitive treatment was external irradiation in 11 cases, cyberknife in two, and high-intensity focused ultrasound in one. Time from definitive treatment to S-RaRP was a mean of 36.5 months. Results: The mean console time was $134.9 \mathrm{~min}$ and blood loss was $99.6 \mathrm{ml}$. Stage $\mathrm{pT2NO}, \mathrm{T} 3 \mathrm{NO}$, and T3N1 were found in eight, four, and two cases, respectively. A positive surgical margin was found in $21.4 \%(3 / 14)$ of the patients. The continence rate was $71.4 \%$ (10/14). Mild stress urinary incontinence (one or two pads/day) was noted in $28.6 \%$ (4/14) of patients. Biochemical recurrence-free status was noted in 11 (78.5\%) patients with a mean follow-up of 32.4 months. Conclusion: S-RaRP is feasible with a low complication rate, good continence rate, and an acceptable potency rate. The shortterm oncological outcomes are encouraging.
\end{abstract}

Reportedly up to two out of three men (34.2-63\%) who receive external-beam radiation therapy (EBRT) for prostate cancer will experience biochemical recurrence (BCR) in the first 3-5 years after treatment $(1,2)$. The options for patients with biochemical recurrence after EBRT for prostate cancer include androgen-deprivation therapy (ADT), salvage radical prostatectomy (SRP), salvage cryotherapy, salvage high-

Correspondence to: Yen-Chuan Ou, Division of Urology, Department of Surgery, Taichung Veterans General Hospital, No. 1650, Sec. 4, Taiwan Boulevard, Taichung 40705, Taiwan, R.O.C. Tel: +886 423741215, Fax: +886 423593160, e-mail: ycou228@gmail.com

Key Words: Laparoscopy, prostate cancer, robotics, salvage radical prostatectomy. intensity focused ultrasound (HIFU), and salvage brachytherapy; however, these modalities are non-curative, with the exception of SRP. Theoretically, SRP provides the possibility of a curative outcome and it is the best management for radiation-failure prostate cancer in young patients. A survey of practice patterns among urologists and radiation oncologists in the United States revealed 25\% would recommend SRP to a patient aged 45-65 years, but only $4 \%$ would recommend it to a 65 - to 75 -year-old patient with biochemical or local failure after definitive irradiation therapy (3). In real-world clinical practice, only four $(0.9 \%)$ out of 430 patients received SRP after EBRT in the CaPSURE database (2). Thus, it appears that patients rarely undergo SRP. A number of factors may explain why SRP is not recommended by the majority of doctors. SRP is more technically demanding than standard open radical prostatectomy due to loss of dissection planes between the prostate and rectum, and the difficulty in differentiating between local and distant recurrence. However, no significant differences in operative time, blood loss or transfusion rate were found between SRP and open radical prostatectomy at one medical center (4). It is worth noting that the SRP group had a higher rate of surgical complications, including urinary tract infection in $20.4 \%$, bladder neck contracture in $47 \%$, urinary retention in $25.3 \%$, urinary fistula in $4.1 \%$, abscess in $3.2 \%$, and rectal injury in $9.2 \%$ (4). Moreover, recovery of continence was achieved in $30 \%$ at year $3(4)$.

Currently, improved patient selection, improved surgical technique, and more experience at centers with greater volume of patients with prostate cancer may have reduced the rates of surgical complications and enhanced outcomes. Robotic-assisted radical prostatectomy is a near gold standard for localized prostate cancer (5). In this study, we evaluated the benefits and drawbacks of salvage roboticassisted radical prostatectomy (S-RaRP) after definitive EBRT, HIFU, or cryotherapy failure in patients with prostate 
cancer. We herein report our experience with 14 cases of SRaRP failure after definitive treatment for prostate cancer. The patients' postoperative functional and oncological outcomes were analyzed.

\section{Patients and Methods}

From December 2005 to June 2016, 1230 cases underwent RaRP performed by a single surgeon (YC Ou). Among them, $14(1.13 \%)$ underwent S-RaRP and were enrolled into this study. After the protocol was approved by our Institutional Review Board (IRB CE15215B), the prospective database was collected. BCR following EBRT, HIFU, or cryotherapy was defined according to the original American Society for Therapeutic Radiation and Oncology (ASTRO) definition with the demonstration of three consecutive increases in serum prostatic-specific antigen (PSA) from a posttreatment (irradiation, HIFU, or cryotherapy) nadir PSA (6).

Patient characteristics are described in Table I. Initial definitive treatment was external irradiation in 11 cases, cyberknife in 2, and HIFU in one. Seven $(50 \%)$ patients also received ADT during definitive treatment. The duration of ADT ranged from 2 to 24 months. The nadir PSA level after definitive treatment ranged from $0.014-8.8 \mathrm{ng} / \mathrm{ml}$ with a mean value of $1.21 \mathrm{ng} / \mathrm{ml}$. A case with a nadir PSA of $8.8 \mathrm{ng} / \mathrm{ml}$ occurred at 13 months after external irradiation only. The mean PSA level at S-RaRP was $6.69 \mathrm{ng} / \mathrm{ml}$ with a range from 0.558 to $25 \mathrm{ng} / \mathrm{ml}$. The mean period from definitive treatment to S-RaRP was 36.5 months

With respect to the surgical technique employed in our series, the steps of S-RaRP procedure were largely the same as those previously described for RaRP (7-9). In the preoperative evaluation, digital rectal examination was the most important method of detecting the mobile prostate from the rectal wall, not fixed prostate or frozen pelvis due to previous irradiation. 3-Tesla multiparametric magnetic resonance imaging is an important modality for detecting the tumor location, amount, involvement, or pelvic lymph node metastasis, while computed tomography and bone scan are valuable for detecting metastatic lymph nodes beyond the pelvic rim, visceral metastasis, and bone metastasis.

The loss of dissection planes from extensive scarring and adhesion after radiation may deter the surgeon from performing $S$ RaRP. The key procedures to overcoming this challenge are dedicated posterior dissection of the prostate, endopelvic fascia dissection, and apical dissection. The dissection of Denonvillier's fascia from the posterior prostate is paramount to preventing rectal injury. Sometimes this plane may be obliterated due to scarring or neovascularization, but with sufficient traction and countertraction, the dissection route to a position near the prostate apex may be recognized. Similarly, the plane of the endopelvic fascia and pelvic side wall may also be hard to recognize. After a well-performed and detailed dissection of the bilateral and posterior aspect, the prostate is freely movable and the risk of unnecessary injury can be avoided.

Neurovascular bundle (NVB) preservation should only be performed in low-risk and young patients, and not only antegrade but also retrograde dissection should be attempted, due to vascularization and bleeding which may obliterate the plane from maximal preservation.

After preservation of anterior and posterior urethral continence components, healthy bladder neck and a long urethral stump would be crucial for early continence. Vesicourethral anastomosis can be performed with barbed continuous suture (3-o V-Loc ${ }^{\mathrm{TM}}$, Covidien) and $200 \mathrm{ml}$ saline irrigation test to secure the anastomosis (10). Foley catheter should be kept for 10 days and postoperative cystourethrogram should not be routinely performed.

Parameters recorded for each surgery included surgeon's console time, estimated blood loss, specimen volume, and complication rate. Specimens were fixed, coated with Indian ink, and cut into systematic stepwise sections at 3-mm intervals (7). The tumor volume, tumor percentage, Gleason score, pathological stage, positive surgical margin rate, angiolymphatic invasion, and nodepositive rate were recorded.

Patient follow-up at 6 weeks after S-RaRP included evaluation of PSA. Continence was defined as having no pad use. Potency was defined as the ability to achieve and maintain satisfactory erections firm enough for sexual intercourse with or without the use of oral phosphodiesterase type 5 inhibitors. Continence and potency were subjectively estimated by the patients at postoperative visits by interview with the treating surgeon. BCR was defined as two consecutive PSA levels of $>0.2 \mathrm{ng} / \mathrm{ml}$ after S-RARP.

\section{Results}

The results of S-RARP are presented in Table II. The characteristics of the three patients with BCR are described in Table III and the outcomes are shown in Table IV. Regarding the D'Amico risk factor before focal treatment, patient 4 was intermediate-risk and both patient 7 and 13 were high-risk. Pathological upstaging was observed in one case, from cT3a to pT3b after S-RaRP. Positive surgical margin was noted in two out of the three patients. All three of these patients received ADT later and one patient developed multiple lung metastases (patient 4) and one developed bone combined with lymph node metastases (patient13) (Table IV).

Four out of the 14 patients suffered from complications. Intra-operative bladder tear occurred in one patient and repair was carried out immediately without urine leakage. One patient suffered from penile ecchymosis after sexual intercourse on post-operative day 28. Two patients suffered from anastomosis stricture and one received urethral sounding once, while another patient needed urethral sounding every 2 to 3 months due to severe scarring and urethral injury during re-insertion of Foley catheter when it became dislodged on post-operative day 6 at a local hospital.

\section{Discussion}

Several studies have demonstrated salvage local treatment for prostate such as SRP could lead to considerably improved BCR-free and metastasis-free survival $(11,12)$. Although some factors such as poorly differentiated tumor and high Gleason score, rapidly rising PSA with short doubling time, or undetectable nadir PSA have been shown to be associated with BCR, no individual factors have definitively excluded the possibility that local salvage therapy may be beneficial (13, 14). Several studies on the use of SRP after definitive radiation 
Table I. Patient characteristics of salvage robotic-assisted radical prostatectomy $(n=14)(S-R a R P)$.

\begin{tabular}{lc}
\hline Parameter & Mean/number \\
\hline Age (years) & $67.8(51-84)$ \\
Initial PSA (ng/ml) & $14.3(3.4-51.3)$ \\
PSA group & \\
$10 \mathrm{ng} / \mathrm{ml}$ & $7(50.0 \%)$ \\
$10-20 \mathrm{ng} / \mathrm{ml}$ & $5(35.7 \%)$ \\
$\geq 20 \mathrm{ng} / \mathrm{ml}$ & $2(14.3 \%)$ \\
Initial stage & \\
cT1 & $6(42.9 \%)$ \\
cT2 & $7(50.0 \%)$ \\
cT3 & $1(7.1 \%)$ \\
Tumor amout at biopsy $(\%)$ & $19.14 \%(4-80 \%)$ \\
Biopsy Gleason score & 6,93 \\
Biopsy Gleason score group & \\
6 & $5(35.7 \%)$ \\
7 & $6(42.9 \%)$ \\
8 & $2(14.3 \%)$ \\
9 & $1(7.1 \%)$ \\
D'Amico risk & \\
Low & $4(28.6 \%)$ \\
Intermediate & $3(21.4 \%)$ \\
High & $7(50.0 \%)$ \\
ADT during RT (n) & $7(50.0 \%)$ \\
ADT duration (months) & 14.6 \\
Nadir PSA (ng/ml) & $1.21(0.014-8.8)$ \\
Nadir PSA $<0.5 \mathrm{ng} / \mathrm{ml}$ & $6(42.3 \%)$ \\
PSA (ng/ml) at S-RaRP & $6.69(0.558-25)$ \\
RT to S-RaRP (months) & $36.5(13-103)$ \\
\hline
\end{tabular}

ADT: Androgen deprivation therapy, RT: radiation therapy, SD: standard deviation, ADT duration 3 months (two patients), 6 months (one patient), 18 months (one patient), 24 months (three patients).

therapy reported that surgical complications and functional outcomes were the major concerns $(4,15)$. Salvage ADT may be the first consideration for patients with BCR after local treatment due to fewer comorbidities; however, despite its systemic treatment effect, it is still not a curative treatment option (16). SRP may provide the possibility of disease-free status with a 5-year BCR-free survival rate of approximately $64 \%$ and a one-year continence rate of $80 \%$ (11).

In the era of robotic surgery, the benefits of 3-dimensional vision and endowrist instruments for deep pelvic surgery have yielded excellent outcomes worldwide over the past 10 years (17). At our Institute, more than 1,200 prostatic surgeries have been carried out with excellent oncology and functional outcomes $(18,19)$. Maintenance of the pneumoperitoneum can reduce bleeding from the venous plexus. High resolution 3-dimensional imaging allows fine dissection, especially when developing the plane of Denonvilliers' fascia, which helps prevent rectal injury and enables maximal preservation of functional urethra. A water-tight anastomosis reduces the incidence of postoperative leakage.
Table II. Peri-operative and result of salvage robotic-assisted radical prostatectomy (S-RaRP).

\begin{tabular}{lc}
\hline Parameter & Mean/number \\
\hline Clinical stage at S-RaRP & \\
T2N0 & $10(71.4 \%)$ \\
T3N0 & $3(21.4 \%)$ \\
T3N1 & $1(7.2 \%)$ \\
Console time (min) & $134.9(105-170)$ \\
EBL (ml) & $99.6(30-160)$ \\
Pathology stage & \\
T2N0 & $8(57.1 \%)$ \\
T3N0 & $4(28.6 \%)$ \\
T3N1 & $2(14.3 \%)$ \\
Lymph node number & $9.8(7-13)$ \\
Specimen volume (ml) & $38(25-80)$ \\
Pathology tumor amount (\%) & $14.36 \%(1-40 \%)$ \\
PSM (n) & $21.4 \%(3 / 14)$ \\
Continence rate* & $71.4 \%(10 / 14)$ \\
Time to continence (months) & $4.4(2$ week-12 months) \\
Potency after bilateral NVB preservation & $66.7 \%(2 / 3)$ \\
Follow up duration (months) & 32,4 \\
BCR-free survival & $78.5 \%(11 / 14)$ \\
\hline
\end{tabular}

EBL: Estimated blood loss, PSM: positive surgical margin, NVB: neurovascular bundle, BCR: biochemical recurrence. *Four patients suffered from stress urinary incontinence needing 1-2 pads per day.

The most notable difference between S-RaRP and RaRP may be the risk of severe adhesion and obscure plane after radiation therapy (20). Surgery begins from the posterior aspect of the prostate, with sharp dissection at Denonvilliers' fascia, which provides early protection of the rectum. After dropping the bladder later, the endopelvic fascia can be opened with sharp dissection and in most situations, this plane may be obliterated and hard to recognize (21). Performing dissection of bladder neck and full mobilization will improve the visualization of prostatatic apex, which may be the most adherent after radiation therapy and easily lead to rectal injury $(22,23)$.

Table V lists the surgical variables of S-RaRP in our series and in the literature. In our perioperative outcomes, the operation time was about 34.9 minutes and the estimated blood loss was $99.6 \mathrm{ml}$, which were similar to values reported in other studies: operative time ranged from 130 to 183 minutes and the estimated blood loss ranged from 75 to $381 \mathrm{ml}$. This indicates that despite the greater difficulty of the surgery, we were still able to achieve an acceptable operative time and limited blood loss. Rectal injury is another risk of concern, but fortunately it was not observed in our series. The only patient who suffered from rectal injury reported by Kaffenberger et al. had an unrecognized pT4 disease (23), and the overall incidence was still low. This may be due to the advantage provided by high-resolution imaging in S-RaRP. The incidence 
Table III. Characteristics of patients with biochemical failure after salvage robotic-assisted radical prostatectomy (S-RaRP).

\begin{tabular}{lccc}
\hline Parameter & No. 4 & No. 7 & No. 13 \\
\hline Age (years) & 73 & 70 & 66 \\
Initial PSA (ng/ml) & 3,4 & 12,03 & 51,3 \\
Initial clinical stage & T1b & T2c & T2c \\
Biopsy tumor amount (\%) & $10 \%$ & $25 \%$ & $40 \%$ \\
Biopsy Gleason score & $3+4=7$ & $4+3=7$ & $4+3=7$ \\
D'Amico risk & Intermediate & High & High \\
Primary treatment & RT & RT & RT \\
ADT during RT, duration (months) & Nil & 24 & 18 \\
Nadir PSA (ng/ml) & 2,1 & 0,9 & 0,3 \\
PSA at S-RaRP (ng/ml) & 7,3 & 15,2 & 18,8 \\
Time from RT to S-RaRP (months) & 27 & 24 & 65 \\
\hline
\end{tabular}

RT: Radiation therapy, ADT: androgen deprivation therapy, PSA: prostatic-specific antigen.

Table IV. Outcomes of biochemical failure after salvage robotic-assisted radical prostatectomy (S-RaRP).

\begin{tabular}{|c|c|c|c|}
\hline Parameter & No. 4 & No. 7 & No. 13 \\
\hline Clinical stage at S-RaRP & $\mathrm{T} 2 \mathrm{c}$ & T3a & $\mathrm{T} 3 \mathrm{aN} 1$ \\
\hline Pathology stage & $\mathrm{T} 2 \mathrm{cN} 0$ & T3bN0 & $\mathrm{T} 3 \mathrm{aN} 1$ \\
\hline Lymph node (positive/yield number) & $0 / 9$ & $0 / 7$ & $3 / 12$ \\
\hline Specimen volume $(\mathrm{ml})$ & 30 & 40 & 45 \\
\hline Tumor amount $(\%)$ & $25 \%$ & $15 \%$ & $45 \%$ \\
\hline PSM & Negative & Positive & Positive \\
\hline Continence (months) & 2 & 3 & *SUI \\
\hline NVB preservation & Nil & Nil & Nil \\
\hline BCR (months) & 5 & 4 & 8 \\
\hline Comment & $\begin{array}{c}\text { Multiple lung metastases } \\
\text { under ADT }\end{array}$ & $\begin{array}{l}\text { No definite local recurrence } \\
\text { or metastases under ADT }\end{array}$ & $\begin{array}{l}\text { Right iliac bone and left } \\
\text { external iliac lymph node } \\
\text { metastases, under ADT, } \\
\text { RT for bone lesion }\end{array}$ \\
\hline
\end{tabular}

NVB: Neurovascular bundle, BCR: biochemical recurrence, ADT: androgen deprivation therapy. *Patient had Parkinsonism with medication.

Table V. Current functional outcomes and cancer control after salvage robotic-assisted radical prostatectomy for radiation-recurrent prostate cancer.

\begin{tabular}{|c|c|c|c|c|c|c|c|c|c|c|c|}
\hline Author & Year & Number & $\begin{array}{l}\text { Op time } \\
\text { (min) }\end{array}$ & $\begin{array}{l}\text { EBL } \\
(\mathrm{ml})\end{array}$ & $\begin{array}{c}\text { Rectal } \\
\text { injury (\%) }\end{array}$ & $\begin{array}{l}\text { Anastomosis } \\
\text { stricture (\%) }\end{array}$ & $\begin{array}{c}\text { Continence } \\
(\%)\end{array}$ & $\begin{array}{l}\text { Potency } \\
(\%)\end{array}$ & $\begin{array}{c}\text { Follow up } \\
\text { (month) }\end{array}$ & $\begin{array}{c}\text { PSM } \\
(\%)\end{array}$ & $\begin{array}{c}\text { BCR-free } \\
\text { rate }(\%)\end{array}$ \\
\hline Boris et al. (20) & 2009 & 11 & 183 & 113 & 9 & 9 & 80 & 18 & 20 & 27 & 73 \\
\hline Eandi et al. (21) & 2010 & 18 & 160 & 150 & 0 & 17 & 33 & 0 & 18 & 28 & 67 \\
\hline Chauhan et al. (22) & 2011 & 15 & 140 & 75 & 0 & NA & 71 & 0 & 5 & 13 & 72 \\
\hline Kaffenberger et al. (23) & 2013 & 34 & 179 & 175 & 2,9 & 8,8 & 44 & 29 & 16 & 26 & 82 \\
\hline Yuh et al. $(24)^{*}$ & 2014 & 51 & 179 & 175 & 2,9 & 22,9 & 45 & 23 & 36 & 31,4 & $57 \%$ at 3 -year \\
\hline Bates et al. (25) & 2015 & 53 & 130 & 120,4 & 0 & 0 & 76,9 & 31,5 & 36 & 18,9 & $67 \%$ at 3 -year \\
\hline Kenny et al. (26) & 2016 & 20 & NA & 381 & 0 & $\begin{array}{c}\text { Anastomosis } \\
\text { leak } 40 \%\end{array}$ & NA & NA & NA & 17 & 78 \\
\hline Current study* & 2017 & 14 & 134,9 & 99,6 & 0 & 14,3 & 71,4 & $66(2 / 3)$ & 32,4 & 21,4 & 78,5 \\
\hline
\end{tabular}

Op time: Operative time, EBL: estimated blood loss, PSM: positive surgical margin, BCR: biochemical recurrence, NA: not assessed. *Positive lymph nodes in $5.9 \%$ in Yuh et al.'s series and $14.3 \%$ in our series. 
of rectal injury in SRP was more common with a prevalence rate of $0-28 \%$ (12).

Anastomosis stricture was another complication with a prevalence rate of $14.3 \%$ in our series. Radiation-induced cell apoptosis, inflammation, vascular injury, and atrophy lead to poorly-oxygenated tissue and eventual tissue scarring, which results in a greater frequency of anastomosis stricture than in normal prostate tissue $(24,25)$. In contrast, continence outcome with pad-free status or only one safety pad was good in our series (71.4\%) and ranged from 33-80\% in the literature. Potency was hard to assess as only three patients were potent before surgery. Bate et al. reported an overall continence rate of $76.9 \%$ and a potency rate of $31.5 \%$ in a series of 53 patients who underwent S-RaRP, which provided the advantage of NVB sparing (25).

In our series, we achieved a relatively low positive surgical margin rate $(21.4 \%)$. Most patients who underwent salvage local treatment had more advanced disease. Greater tissue density, obscure plane, and advance tumor behavior may lead to a higher incidence of positive surgical margin, which ranged from 13 to $31.4 \%$ in the literature. Most positive surgical margins occurred at the prostattic apex with an overall rate of $78 \%$ (23). Consistent with previous studies, our findings showed that S-RaRP provided patients with the possibility of becoming diseasefree, with a BCR-free survival rate of $78.5 \%$ at a mean follow-up of 32.4 months.

Although S-RaRP achieved an excellent oncology outcome and an acceptable functional outcome, it is important to note that this surgical modality should be applied on an individual basis after the patient has undergone a thorough evaluation to avoid unnecessary surgery.

In order to attain the benefits of a reduced complication rate and a better surgical outcome provided by S-RaRP, the clinician must perform patient selection according to certain criteria. Several previous studies have demonstrated a number of important prognostic variables that appear to predict oncology outcome. Kaffenberger et al. reported PSA doubling time and Gleason score at original diagnosis were two major independent risk factors for BCR (23). Yuh et al. reported that high PSA and extracapsular extension may be related to early BCR, with an estimated 3-year BCR rate of $43 \%$ (24). In summary, most patients who underwent SRaRP had a relatively advanced disease status with potential distant metastasis and therefore patient selection is of paramount importance. Preoperative bone scan and computed tomography is crucial for detecting distal metastatic lesions to prevent unnecessary surgery.

In our single-institute experience, our findings indicate that S-RaRP was capable of achieving good oncological control with an excellent BCR free-rate, as well as satisfactory symptomatic control. Most of the patients that received radiation suffered from low urinary tract symptoms related to chronic obstruction which were resolved after surgical intervention. Although some patients suffered from incontinence, an experienced surgeon can expect to achieve excellent overall functional outcome. Our outcomes showed that S-RaRP resulted in fewer surgical complications such as low estimated blood loss and no rectal injury and thus we propose that this modality may offer suitable candidate patients the possibility of becoming cancer-free.

There were some limitations to our study. This was a retrospective investigation with a limited number of patients and thus these findings should be interpreted with caution in clinical practice. Moreover, because prostate cancer is relatively slow-growing, further long-term follow-up may be needed to further clarify the beneficial effect of S-RaRP on survival rates.

\section{Conclusion}

S-RaRP is a technically feasible operation with a low complication rate. Operative time was increased but there was no significant increase in blood loss. Continence rate was good and potency rate was acceptable. Short-term oncological outcomes are encouraging; however, longer follow-up is necessary to determine the long-term survival benefits.

\section{Conflicts of Interest}

None of the contributing Authors have any conflict of interest, including specific financial interests or relationships and affiliations relevant to the subject matter or materials discussed in the manuscript.

\section{References}

1 Shipley WU, Thames HD, Sandler HM, Hanks GE, Zietman AL, Perez CA, Kuban DA, Hancock SL and Smith CD: Radiation therapy for clinically localized prostate cancer: a multiinstitutional pooled analysis. JAMA 281: 1598-1604, 1999.

2 Agarwal PK, Sadetsky N, Konety BR, Resnick MI, Carroll PR; Cancer of the Prostate Strategic Urological Research Endeavor (CaPSURE): Treatment failure after primary and salvage therapy for prostate cancer: likelihood, patterns of care, and outcomes. Cancer 112: 307-314, 2008.

3 Sylvester J, Grimm P, Blasco J, Meier R, Spiegel J, Heaney C and Cavanagh $\mathrm{W}$ : The role of androgen ablation in patients with biochemical or local failure after definitive radiation therapy: a survey of practice patterns of urologists and radiation oncologists in the United States. Urology 58: 65-70, 2001.

4 Gotto GT, Yunis LH, Vora K, Eastham JA, Scardino PT and Rabbani F: Impact of prior prostate radiation on complications after radical prostatectomy. J Urol 184: 136-142, 2010.

5 Sood A, Jeong W, Peabody JO, Hemal AK and Menon M: Robot-assisted radical prostatectomy: inching toward gold standard. Urol Clin North Am 41: 473-484, 2014. 
6 Consensus Statement: Guidelines for PSA Following Radiation therapy. American Society for Therapeutic Radiology and Oncology Consensus Panel. Int J Radiat Oncol Biol Phys 37(5): 1035-1041, 1997.

7 Ou YC, Yang CR, Wang J, Yang CK, Cheng CL, Patel VR, and Tewari AK: The learning curve for reducing complications of robotic-assisted laparoscopic radical prostatectomy by a single surgeon. BJU Int 108: 420-425, 2011.

8 Ou YC, Hung SW, Wang J, Yang CK, Cheng CL and Tewari AK: Retro-apical transection of the urethra during robot-assisted laparoscopic radical prostatectomy in an Asian population. BJU Int 110: E57-E63, 2012.

9 Ou YC, Yang CK, Wang J, Hung SW, Cheng CL, Tewari AK and Patel VR: The trifecta outcome in 300 consecutive cases of robotic-assisted laparoscopic radical prostatectomy according to D'Amico risk criteria. Eur J Surg Oncol 39: 107-113, 2013.

$10 \mathrm{Ou}$ YC, Yang CK, Chang KS, Wang J, Hung SW, Tung MC, Tewari AK and Patel VR: The surgical learning curve for robotic-assisted laparoscopic radical prostatectomy: experience of a single surgeon with 500 cases in Taiwan. Asian J Androl 16: 728-734, 2014.

11 Chade DC, Shariat SF, Cronin AM, Savage CJ, Karnes RJ, Blute ML, Briganti A, Montorsi F, van der Poel HG, Van Poppel H, Joniau S, Godoy G, Hurtado-Coll A, Gleave ME, Dall'Oglio M, Srougi M, Scardino PT and Eastham JA: Salvage radical prostatectomy for radiation-recurrent prostate cancer: a multiinstitutional collaboration. Eur Urol 60(2): 205-210, 2011.

12 Chade DC, Eastham J, Graefen M, Hu JC, Karnes RJ, Klotz L, Montorsi F, van Poppel H, Scardino PT and Shariat SF: Cancer control and functional outcomes of salvage radical prostatectomy for radiation-recurrent prostate cancer: a systematic review of the literature. Eur Urol 61(5): 961-971, 2012.

13 Rodrigues NA, Chen MH, Catalona WJ, Roehl KA, Richie JP and D'Amico AV: Predictors of mortality after androgendeprivation therapy in patients with rapidly rising prostatespecific antigen levels after local therapy for prostate cancer. Cancer 107: 514-520, 2006.

14 Slovin SF, Wilton AS, Heller G and Scher HI: Time to detectable metastatic disease in patients with rising prostate-specific antigen values following surgery or radiation therapy. Clin Cancer Res 11: 8669-8673, 2005.

15 Darras J, Joniau S and Van Poppel H: Salvage radical prostatectomy for radiorecurrent prostate cancer: indications and results. Eur J Surg Oncol 32: 964-969, 2006.

16 Cooperberg MR, Vickers AJ, Broering JM and Carroll PR: Comparative risk-adjusted mortality outcomes after primary surgery, radiotherapy, or androgen-deprivation therapy for localized prostate cancer. Cancer 22: 5226-5234, 2010.

17 Ahmed K, Khan MS, Vats A, Nagpal K, Priest O, Patel V, Vecht JA, Ashrafian H, Yang GZ, Athanasiou T and Darzi A: Current status of robotic-assisted pelvic surgery and future developments. Int J Surg 7(5): 431-440, 2009.
18 Ou YC, Yang CK, Kang HM, Chang KS, Wang J, Hung SW, Tung MC, Tewari AK and Patel VR: Pentafecta outcomes of 230 cases of robotic-assisted radical prostatectomy with bilateral neurovascular bundle preservation. Anticancer Res 35(9): 50075013, 2015.

19 Hung SC, Ou YC, Cheng CL, Hung SW, Ho HC, Chiu KY, Wang SS, Chen CS, Li JR and Yang CK: Standardized procedure of roboticIassisted laparoscopic radical prostatectomy from case 1 to case 1200. Urol Science 27(4): 199-207, 2016.

20 Boris RS, Bhandari A, Krane LS, Eun D, Kaul S and Peabody JO: Salvage robotic-assisted radical prostatectomy: initial results and early report of outcomes. BJU Int 103(7): 952-956, 2009.

21 Eandi JA, Link BA, Nelson RA, Josephson DY, Lau C, Kawachi MH and Wilson TG: Robotic-assisted laparoscopic salvage prostatectomy for radiation resistant prostate cancer. J Urol 183(1): 133-137, 2010.

22 Chauhan S, Patel MB, Coelho R, Liss M, Rocco B, Sivaraman AK, Palmer KJ, Coughlin GD, Ferrigni RG, Castle EP, Ahlering TE, Parra-Davila E and Patel VR: Preliminary analysis of the feasibility and safety of salvage robot-assisted radical prostatectomy after radiation failure: multi-institutional perioperative and short-term functional outcomes. J Endourol 25(6): 1013-1019, 2011.

23 Kaffenberger SD, Keegan KA, Bansal NK, Morgan TM, Tang DH, Barocas DA, Penson DF, Davis R, Clark PE, Chang SS, Cookson MS, Herrell SD and Smith JA Jr.: Salvage roboticassisted laparoscopic radical prostatectomy: a single institution, 5-year experience. J Urol 189(2): 507-513, 2013.

24 Yuh B, Ruel N, Muldrew S, Mejia R, Novara G, Kawachi M and Wilson T: Complications and outcomes of salvage robot-assisted radical prostatectomy: a single-institution experience. BJU Int 113(5): 769-776, 2014.

25 Bates AS, Samavedi S, Kumar A, Mouraviev V, Rocco B, Coelho R, Palmer K and Patel VR: Salvage robot-assisted radical prostatectomy: A propensity matched study of perioperative, oncological and functional outcomes. Eur J Surg Oncol 41(11): 1540-1546, 2015.

26 Kenny PA, Nawaf CB, Mustafa M, Wen S, Wszolek MF, Pettaway CA, Ward JF, Davis JW and Pisters LL: Roboticassisted laparoscopic versus open salvage radical prostatectomy following radiotherapy. Can J Urol 23(3): 8271-8277, 2016.

Received February 14, 2017

Revised March 7, 2017

Accepted March 13, 2017 